\title{
Risk management in industrial projects using structural equation modeling
}

\author{
Mohammad Zaripour ${ }^{a^{*}}$ and Bita Zaripour ${ }^{\mathrm{b}}$
}

${ }^{a}$ Master student, Department of Industrial Engineering, Islamic Azad University, South Tehran, Iran

${ }^{b}$ Master student, Department of Industrial Engineering Iran University of Science and Technology, Tehran, Iran

\section{CHRONICLE A B T T A C T}

Article history:

Received January 5, 2016

Received in revised format June 15,2016

Accepted July 19, 2016

Available online

July 21, 2016

Keywords:

Risk Management

Structural equation modeling

Industrial projects

\begin{abstract}
This paper presents an empirical investigation to study the effects of different factors influencing on accomplishment of projects in Iranian oil industry. The proposed study designs a questionnaire consists of 50 questions in Likert scale with seven factors including sanctions, economy, scheduling, contractor management weaknesses, cultural/social, force majeure and contractee. The study considers the effects of these factors in three categories; namely risk of project scheduling, risk in project cost and risk in management weakness. Using structural equation modeling, the study confirms that all three factors influence on the success of oil projects. In other words, The results have indicated that budgeting as well as cost accounting is the most important factor in accomplishment of oil projects followed by weakness in management and having an appropriate scheduling.
\end{abstract}

\section{Introduction}

During the past few years, there have been tremendous efforts on detecting important risks involved in executing big industrial projects (Craighead et al., 2007; Olson \& Dash Wu, 2010). Risk identification often generates nothing more than a long list of risks, which can be difficult to manage. The list is normally prioritized to detect, which risks should be considered first, but this does not give any insight into the structure of risk on the project (Hillson, 2003). Tang and Musa (2011) investigated the research development in supply chain risk management (SCRM). The study identified and classified the potential risk related to various flows, namely material, cash and information flows. Thun and Hoenig (2011) performed an empirical analysis of supply chain risk management practices based on a survey with 67 manufacturing firms conducted in the German automotive industry and identified supply chain risks by analyzing their likelihood to happen and their potential effects on the supply chain. According to Qazi et al. (2016) "Project complexity has been extensively explored in the literature because of its contribution towards the failure of major projects in terms of cost and time overruns". Qazi et al. (2016)

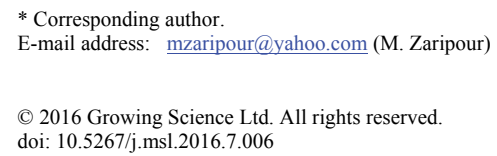


proposed a method, which helps capturing interdependency among project complexity, complexity induced risks and project objectives.

Cervone (2006) shed light on the issues associated with risk management in digital library projects as well as techniques for mitigating risk in these projects. ALNabhani et al. (2016) discussed the relative importance of public participation in legislation of TENORM risk management in the oil and gas industry. Salazar-Aramayo et al. (2013) shed light on factors, which influence Exploration and Production $(\mathrm{E} \& \mathrm{P})$ project management success and corporate financial performance using structural equation modeling (SEM) methodology for a case study in a large Brazilian oil company. Marcella and Rowley (2015) presented an exploration of the extent to which project management tools and techniques could be implemented across creative industries through a comprehensive investigation of their application in the fashion industry in the North East of Scotland. Bjerga and Aven (2015) discussed management of risk for a case of large uncertainties and the adaptation of risk management in such circumstances. They used a case from the oil and gas industry to gain insights into how adaptive risk management could be used when giving due attention to the knowledge and uncertainty aspects of risk.

\section{The proposed study}

This paper presents an empirical investigation to study the effects of different factors influencing on accomplishment of projects in oil industry. The proposed study designs a questionnaire consists of 50 questions in Likert scale with seven factors including sanctions, economy, scheduling, contractor management weaknesses, cultural/social, force majeure and contractee. Details of the questionnaire is given in Table 8 in Appendix. The study considers the effects of these factors in three categories; namely risk of project scheduling, risk in project cost and risk in management weakness. Fig. 1 demonstrates the structure of the proposed study,

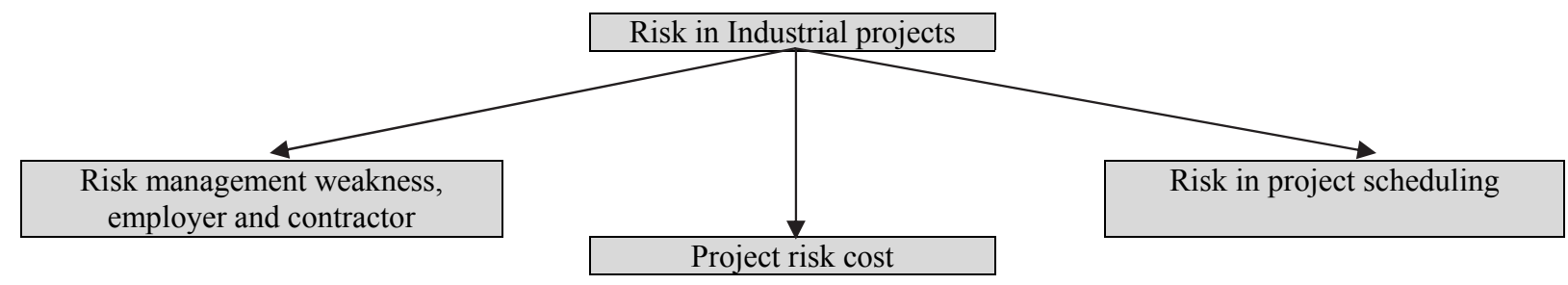

Fig. 1. The structure of the proposed study

The current research is a practical and applicable type of research and it is descriptive and inferential in terms of collecting data which explains the features of the sample and then generalizes these features to the statistical population. In this study, the descriptive research has been applied in survey type, because the means of collecting data (questionnaires) has been distributed and then collected in the samples of statistical population. The methods of collecting data in this research is of library and field operation kind. Thus, it can be generally said that this study is a practical descriptive survey research of correlation type analyzed by using exploratory function analysis for the first and second time and by the helping of SPSS and factor analysis together with Amos application and afterwards, by utilizing the factor analysis, the structural model was presented. Due to the fact that this is a case study and related to Derik energy company, the statistical population of this study is of accessible type in sampling method including the present managers, experts and employees and the volume of the samples (X) for explorative function analysis $(5 \times \mathrm{q}<\mathrm{x}<15 \times \mathrm{q})$ and " $\mathrm{q}$ " stands for the number of questions in questionnaires Kline, Paul. (1994). First, the effective variables of the structures in the first step of Delfi were identified by the experts and then the effective variables were added from the sources including articles and the books after being collected. The common items of sources and elites were omitted and in the second step of Delfi elites, 38 effective variables of structures were ranked between the scales of 
1 and 10 and 80 percent of the variables with high ranking were kept and the others were deleted and ultimately, "q" as the number of questions in questionnaires was designed equal to 31 effective variables in Likert scale between 1 and 5 and its content validity was confirmed the experts and the thesis supervisors and thesis advisors. The sample volume $n=172$ is considered between the minimum of 150 and maximum of 453. The questionnaires are distributed among the experts and managers and employees and in the final step, the questionnaires were collected and the entering of information and reforming the lost data by means of the median method were carried out (Draycott, \& Kline, 1994). Fig. 2 demonstrates personal characteristics of the participants.

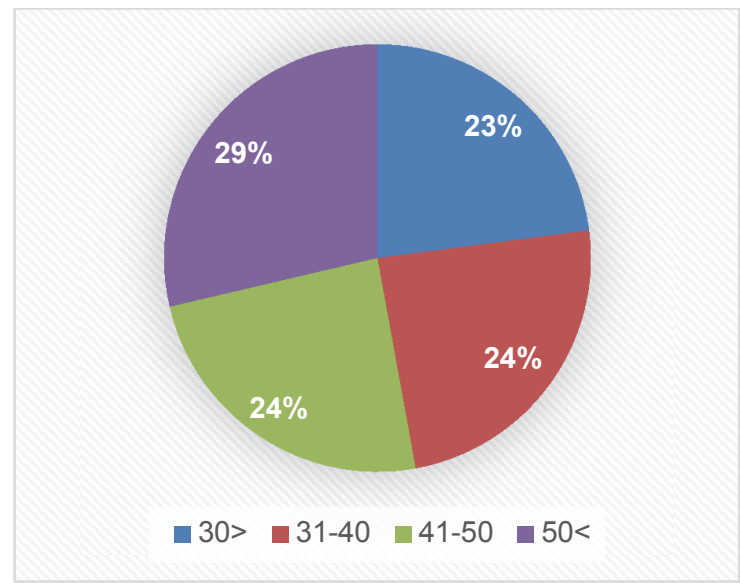

Age

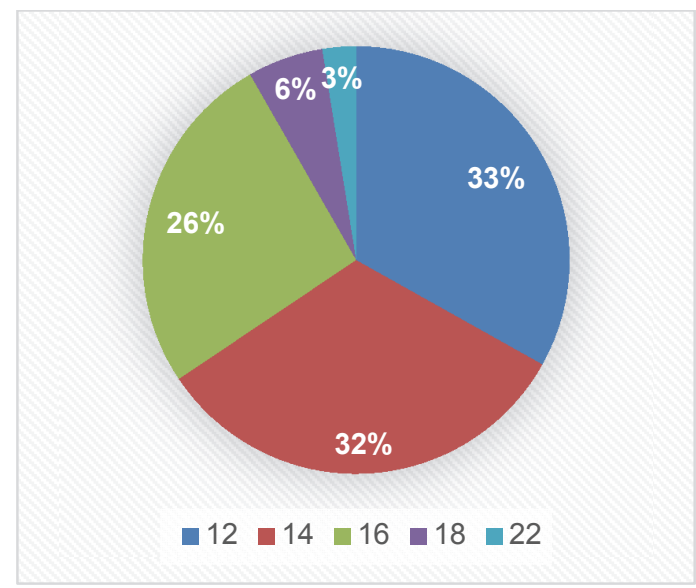

Years of education

Fig. 2. Personal characteristics of the participants

As we can observe from the results of Fig. 2, most participants in our survey are middle aged with good university educations. The proposed study of this paper uses structural equation modeling (SEM) to measure the effects of three mentioned risk factors on accomplishment of industrial projects. Fig. 3 demonstrates the preliminary results of the implementation of the proposed study. The SEM has been extensively used for accomplishing different projects (Seyedaliakbar et al., 2016; Seyedaliakbar \& Zaripour, 2017).

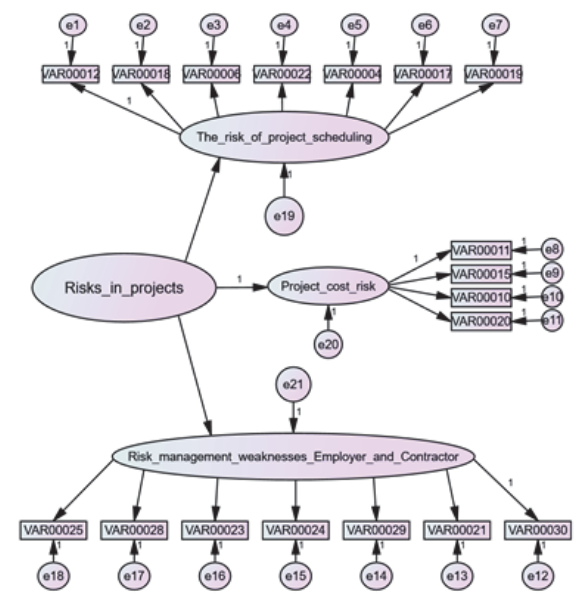

Fig. 3. The results of the implementation of structural equation modeling

As we can observe from the results of Fig. 3 and Table 1, most statistics are not within desirable values and we have to make some changes to make the model more appropriate by considering the 
relationships among internal variables. Fig. 4 demonstrates the revised model after the changes have been made (See Appendix for more details of the method used). As we can observe from the results of Table 2, all statistics are within desirable limits. Chi-Square value is more than the desirable value, and root mean square error of approximation (RMSEA) is less than $10 \%$. Other statistics such as Goodness of fit index (GFI), Adjusted goodness of fit index (AGFI), Non-normed fit (NFI) index, etc. have maintained values of greater than 0.9 , which confirm the overall model. Therefore, We can examine the hypotheses of the survey based on the results.

\section{Table 1}

The results of statistical observations

\begin{tabular}{lllll}
\hline & Attribute & Symbol & Value & Desired value \\
\hline \multirow{3}{*}{ Absolute fit attributes } & Chi-Square & $\chi^{2}$ & 0.000 & $>0.05$ \\
& Goodness of fit index & GFI & 0.885 & $>0.90$ \\
& Adjusted goodness of fit index & AGFI & 0.858 & $>0.90$ \\
\hline & Non-normed fit index & NNFI & 0.786 & $>0.90$ \\
& Normed Fit Index & NFI & 0.662 & $>0.90$ \\
Comparative fit index & Comparative Fit Index & CFI & 0.809 & $>0.90$ \\
& Bollen's Incremental Fit Index & IFI & 0.815 & $>0.90$ \\
\hline \multirow{3}{*}{ Economic fitness } & Parsimonious normed fit index & PNFI & 0.589 & $>0.5$ \\
& Root mean square error of approximation & RMSEA & 0.055 & $<0.05$ \\
& Relative chi-square & CMIN/df & 1.802 & $<2$ \\
\hline Sample adequacy & Sample adequacy & Hotrel & 120 & $>200$ \\
\hline
\end{tabular}

Table 2

The results of statistical observations

\begin{tabular}{lllll}
\hline & Attribute & Symbol & Value & Desired value \\
\hline \multirow{3}{*}{ Absolute fit attributes } & Chi-Square & $\chi^{2}$ & 0.06 & $>0.05$ \\
& Goodness of fit index & GFI & 0.928 & $>0.90$ \\
& Adjusted goodness of fit index & AGFI & 0.906 & $>0.90$ \\
\hline & Non-normed fit index & NNFI & 0.958 & $>0.90$ \\
& Normed Fit Index & NFI & 0.798 & $>0.90$ \\
Comparative fit index & Comparative Fit Index & CFI & 0.965 & $>0.90$ \\
& Bollen's Incremental Fit Index & IFI & 0.966 & $>0.90$ \\
\hline \multirow{2}{*}{ Economic fitness } & Parsimonious normed fit index & PNFI & 0.669 & $>0.5$ \\
& Root mean square error of approximation & RMSEA & 0.024 & $<0.05$ \\
& Relative chi-square & CMIN/df & 1.55 & $<2$ \\
\hline Sample adequacy & Sample adequacy & Hotrel & 220 & $>200$ \\
\hline
\end{tabular}

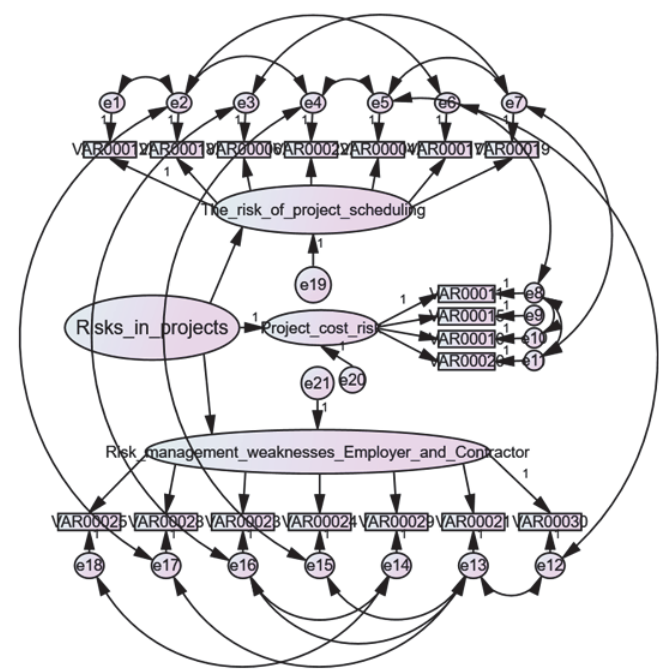

Fig. 4. The revised model

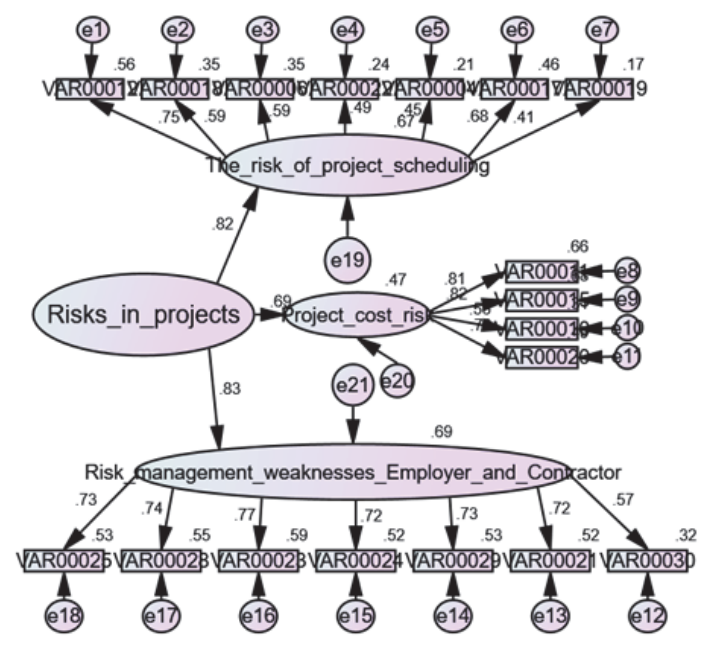

Fig. 5. The results of standard coefficients 
Fig. 5 shows the results of standard coefficients on different factors. Moreover, Table 3 shows the results of our survey.

\section{Table 3}

The results of comparison of details of the fitting model

\begin{tabular}{llcccccc}
\hline Variable & & & Estimate & S.E. & C.R. & P & Label \\
\hline The_risk_of_project_scheduling & $\rightarrow$ & VAR00012 & 1 & & & & \\
The_risk_of_project_scheduling & $\rightarrow$ & VAR00018 & 0.478 & 0.088 & 5.421 & $* * *$ & par_1 \\
The_risk_of_project_scheduling & $\rightarrow$ & VAR00006 & 1.035 & 0.152 & 6.809 & $* * *$ & par_2 \\
The_risk_of_project_scheduling & $\rightarrow$ & VAR00022 & 0.666 & 0.139 & 4.8 & $* * *$ & par_3 \\
The_risk_of_project_scheduling & $\rightarrow$ & VAR00004 & 0.659 & 0.128 & 5.151 & $* * *$ & par_4 \\
The_risk_of_project_scheduling & $\rightarrow$ & VAR00017 & 0.988 & 0.135 & 7.292 & $* * *$ & par_5 \\
The_risk_of_project_scheduling & $\rightarrow$ & VAR00019 & 0.56 & 0.111 & 5.052 & $* * *$ & par_6 \\
\hline Project_cost_risk & $\rightarrow$ & VAR00011 & 1 & & & & \\
Project_cost_risk & $\rightarrow$ & VAR00015 & 0.946 & 0.115 & 8.206 & $* * *$ & par_7 \\
Project_cost_risk & $\rightarrow$ & VAR00010 & 0.437 & 0.074 & 5.922 & $* * *$ & par_8 \\
Project_cost_risk & $\rightarrow$ & VAR00020 & 0.897 & 0.107 & 8.412 & $* * *$ & par_9 \\
\hline Risk_management_weaknesses_Employer_and_Contractor & $\rightarrow$ & VAR00030 & 1 & & & & \\
Risk_management_weaknesses_Employer_and_Contractor & $\rightarrow$ & VAR00021 & 1.21 & 0.18 & 6.734 & $* * *$ & par_10 \\
Risk_management_weaknesses_Employer_and_Contractor & $\rightarrow$ & VAR00029 & 1.066 & 0.15 & 7.084 & $* * *$ & par_11 \\
Risk_management_weaknesses_Employer_and_Contractor & $\rightarrow$ & VAR00024 & 1.213 & 0.159 & 7.634 & $* * *$ & par_12 \\
Risk_management_weaknesses_Employer_and_Contractor & $\rightarrow$ & VAR00023 & 1.366 & 0.183 & 7.474 & $* * *$ & par_13 \\
Risk_management_weaknesses_Employer_and_Contractor & $\rightarrow$ & VAR00028 & 1.126 & 0.148 & 7.615 & $* * *$ & par_14 \\
Risk_management_weaknesses_Employer_and_Contractor & $\rightarrow$ & VAR00025 & 1.113 & 0.163 & 6.831 & $* * *$ & par_15 \\
\hline
\end{tabular}

\section{Conclusion and discussion}

Based on the results of the survey, we are now ready to discuss of testing different hypotheses of the survey. The first hypothesis of the survey investigates the relationship between the risk in industrial projects and an appropriate scheduling of the projects. Table 4 shows the results.

\section{Table 4}

The results of testing the relationship between risk in industrial projects and an appropriate scheduling of the projects

\begin{tabular}{lccc}
\hline & Correlation & Sig. & Result \\
\hline Appropriate scheduling $\rightarrow$ Risk in project & 0.755 & 0.000 & Confirmed \\
\hline
\end{tabular}

According to the results of Table 4, we observe a positive and significant correlation between having an appropriate scheduling and risk in project. In other words, when there is an appropriate scheduling for accomplishment of a project, one may expect a reduction on risk involved in industrial projects. Table 5 demonstrates the results of testing the effect of cost involved in accomplishment of a project and the cost and budget.

\section{Table 5}

The results of testing the relationship between risk in industrial projects and cost of the projects

\begin{tabular}{lccc}
\hline & Correlation & Sig. & Result \\
\hline Budgeting the project $\rightarrow$ Risk in project & 0.75 & 0.000 & Confirmed \\
\hline
\end{tabular}

The results also confirm that there was a positive and meaningful relationship between these two variables and we can confirm the second hypothesis of the survey. Thus, we may expect to reduce the risk involved in project by appropriately assigning cost and budget. Finally, the last hypothesis of the survey studies the relationship between weakness in management and risk involved in accomplishment of projects, which are summarized in Table 6 as follows, 
Table 6

The results of testing the relationship between risk in industrial projects and weakness in management

\begin{tabular}{lccc}
\hline & Correlation & Sig. & Result \\
\hline Weakness in management $\rightarrow$ Risk in project & 0.14 & 0.023 & Confirmed \\
\hline
\end{tabular}

The results of the survey have confirmed the relationship between these two variables and confirm the last hypotheses. Finally, Table 7 shows the results of standard coefficients.

\section{Table 7}

The results of standard coefficients

\begin{tabular}{lccc}
\hline & Standard coefficient & Sig. & Result \\
\hline Appropriate scheduling $\rightarrow$ Risk in project & 0.44 & 0.000 & Confirmed \\
\hline Budgeting the project $\rightarrow$ Risk in project & 0.66 & 0.000 & Confirmed \\
\hline Weakness in management $\rightarrow$ Risk in project & 0.62 & 0.000 & Confirmed \\
\hline
\end{tabular}

The results of Table 7 have indicated that budgeting \& cost accounting is the most important factor in accomplishment in projects involved in oil industry followed by weakness in management and having appropriate scheduling. The results of this survey are consistent with other findings reported earlier in the literature. Salazar-Aramayo et al. (2013), for instance, presented similar implementation by using a conceptual model for project management of exploration and production in the oil and gas industry in Brazil and reported that the model could contribute substantially to the firm because it was a global representation of the main factors for improving E\&P project management. Capolei et al. (2015) reported that in oil production optimization, we normally plan to maximize a deterministic scalar performance index such as the profit over the expected reservoir lifespan. However, when there are some uncertainty in the existing parameters, the profit results in a random variable, which could assume a range of values depending on the value of the uncertain parameters. They considered the concept of risk and explored how to handle the risk by applying appropriate risk measures. 


\section{References}

ALNabhani, K., Khan, F., \& Yang, M. (2016). The importance of public participation in legislation of TENORM risk management in the oil and gas industry. Process Safety and Environmental Protection, 102, 606-614.

Bjerga, T., \& Aven, T. (2015). Adaptive risk management using new risk perspectives-an example from the oil and gas industry. Reliability Engineering \& System Safety, 134, 75-82.

Capolei, A., Foss, B., \& Jørgensen, J. B. (2015). Profit and risk measures in oil production optimization. IFAC-Papers OnLine, 48(6), 214-220.

Cervone, H. F. (2006). Project risk management. OCLC Systems \& Services: International Digital Library Perspectives, 22(4), 256-262.

Craighead, C. W., Blackhurst, J., Rungtusanatham, M. J., \& Handfield, R. B. (2007). The severity of supply chain disruptions: design characteristics and mitigation capabilities. Decision Sciences, 38(1), 131-156.

Draycott, S. G., \& Kline, P. (1994). Further investigation into the nature of the BIP: A factor analysis of the BIP with primary abilities. Personality and individual Differences, 17(2), 201-209.

Hillson, D. (2003). Using a risk breakdown structure in project management.Journal of Facilities Management, 2(1), 85-97.

Marcella, M., \& Rowley, S. (2015). An exploration of the extent to which project management tools and techniques can be applied across creative industries through a study of their application in the fashion industry in the North East of Scotland. International Journal of Project Management, 33(4), 735-746.

Olson, D. L., \& Dash Wu, D. (2010). A review of enterprise risk management in supply chain. Kybernetes, 39(5), 694-706.

Qazi, A., Quigley, J., Dickson, A., \& Kirytopoulos, K. (2016). Project Complexity and Risk Management (ProCRiM): Towards modelling project complexity driven risk paths in construction projects. International Journal of Project Management, 34(7), 1183-1198.

Salazar-Aramayo, J. L., Rodrigues-da-Silveira, R., Rodrigues-de-Almeida, M., \& de Castro-Dantas, T. N. (2013). A conceptual model for project management of exploration and production in the oil and gas industry: The case of a Brazilian company. International Journal of Project Management,31(4), 589-601.

Seyedaliakbar, S., Zaripour, M., Zangeneh, G \& Sadeghi, H. (2016). An investigation into the determinants of customer satisfaction. Uncertain Supply Chain Management, 4(4), 263-268.

Seyedaliakbar, S \& Zaripour, M. (2017). Exploring effective factors on privatization, firm performance and export development: Evidence from steel industry. Accounting, 3(1), 1-10.

Tang, O., \& Musa, S. N. (2011). Identifying risk issues and research advancements in supply chain risk management. International Journal of Production Economics, 133(1), 25-34.

Thun, J. H., \& Hoenig, D. (2011). An empirical analysis of supply chain risk management in the German automotive industry. International Journal of Production Economics, 131(1), 242-249.

\section{Acknowledgement}

The authors would like to thank the anonymous referees for constructive comments on earlier version of this paper. 


\section{Appendix}

The questionnaire of the survey consists of 50 questions in different categories summarized in Table 8 as follows,

\section{Table 8}

The questionnaire of the survey

\begin{tabular}{|c|c|c|c|}
\hline Variable & & & Description \\
\hline \multirow{7}{*}{ Embargo } & 1 & 1 & Commercial embargo \\
\hline & 2 & 2 & Financial embargo \\
\hline & 3 & 3 & Technological embargo \\
\hline & 4 & 4 & Transportation embargo \\
\hline & 5 & 5 & Limitation in the number of available suppliers \\
\hline & 6 & 6 & Work with low quality suppliers \\
\hline & 7 & 1 & $\begin{array}{l}\text { Lack of existence of necessary infrastructures for accomplishment of the industrial } \\
\text { project }\end{array}$ \\
\hline \multirow{7}{*}{ Economic } & 8 & 2 & Price fluctuation \\
\hline & 9 & 3 & Inflation \\
\hline & 10 & 4 & Changes in currency exchange rate \\
\hline & 11 & 5 & Unsuitable estimate in cost of project \\
\hline & 12 & 6 & Revenue reduction and lack of employment satisfaction \\
\hline & 13 & 7 & Lack of customer satisfaction \\
\hline & 14 & 8 & Inefficient contractors \\
\hline \multirow{9}{*}{ Scheduling } & 15 & 1 & Time limitation for supplement of goods and equipment \\
\hline & 16 & 2 & Error in scheduling project \\
\hline & 17 & 3 & Tight schedule for the accomplishment of the project \\
\hline & 18 & 4 & Inefficient contractors \\
\hline & 19 & 5 & Damage in transportation of equipment \\
\hline & 20 & 6 & Delay in transportation of equipment \\
\hline & 21 & 7 & Delay in production and construction of equipment \\
\hline & 22 & 8 & The effects of contractors' insufficient cash in accomplishment of project \\
\hline & 23 & 9 & The effects of contractee's insufficient cash in accomplishment of project \\
\hline \multirow{13}{*}{$\begin{array}{l}\text { Weakness in } \\
\text { management }\end{array}$} & 24 & 1 & $\begin{array}{l}\text { Lack of knowledge of contractor about tools and techniques associated with project } \\
\text { activities }\end{array}$ \\
\hline & 25 & 2 & Lack of commitment on behalf of contractor for the implementation of project activities \\
\hline & 26 & 3 & The lack of skilled manpower \\
\hline & 27 & 4 & The lack of skilled employees \\
\hline & 28 & 5 & Rework to fix mistakes, resulting in delays in business \\
\hline & 29 & 6 & Delays in clearance forms in custom section \\
\hline & 30 & 7 & Damage to goods in transit \\
\hline & 31 & 8 & Damage in goods and equipment \\
\hline & 32 & 9 & Poor labor productivity \\
\hline & 33 & 10 & Weak mobilization \\
\hline & 34 & 11 & Violating the scope and terms of the contract \\
\hline & 35 & 12 & The misallocation of human resources and equipment \\
\hline & 36 & 13 & $\begin{array}{l}\text { Lack of supervision of installation and commissioning of machinery and project } \\
\text { Management }\end{array}$ \\
\hline \multirow{3}{*}{ Cultural/Social } & 37 & 1 & Cultural conflict and sabotage residents \\
\hline & 38 & 2 & Theft and theft of equipment installed \\
\hline & 39 & 3 & Inappropriate industrial culture workforce \\
\hline \multirow[t]{2}{*}{ Force majeure } & 40 & 1 & Natural disasters such as flood, earthquake, etc. \\
\hline & 41 & 2 & Fire and theft \\
\hline \multirow{9}{*}{ Contractee } & 42 & 1 & Lack of knowledge and familiarity with application of modern administrative methods \\
\hline & 43 & 2 & Lack of access to records of similar projects \\
\hline & 44 & 3 & Lack of coordination and the necessary support staff of the project \\
\hline & 45 & 4 & The lack of systematic approach between the sectors related to the project \\
\hline & 46 & 5 & Improper or incomplete economic feasibility studies \\
\hline & 47 & 6 & Delays in resolving cases of contract \\
\hline & 48 & 7 & Posing tight schedule to contractor \\
\hline & 49 & 8 & Intervene and breaking the law by the contractee \\
\hline & 50 & 9 & Inefficient system of evaluation and selection of contractors \\
\hline
\end{tabular}


The assessment of normality test is executed in Table 9. According to the results of Table 9, some of the variables have maintained Kurtosis values of less than 2.58 and we can observe that 18 variables are not normally distributed. To handle this problem, we use maximum likelihood estimator and Bootstrap. Table 10 shows the Mahalanobis distance for observations farthest from the centroid.

Table 9

The assessment of normality

\begin{tabular}{ccccccc}
\hline Variable & Min & Max & Skew & C.R. & Kurtosis & C.R. \\
\hline V19 & 1.000 & 5.000 & -1.132 & -5.790 & 2.469 & 6.315 \\
V17 & 1.000 & 5.000 & -.661 & -3.383 & -.025 & -.064 \\
V4 & 1.000 & 5.000 & -.596 & -3.047 & .143 & .365 \\
V22 & 2.000 & 5.000 & -.220 & -1.124 & -.977 & -2.499 \\
V6 & 1.000 & 5.000 & -.497 & -2.544 & -.489 & -1.250 \\
V18 & 2.000 & 5.000 & -1.109 & -5.671 & .480 & 1.227 \\
V12 & 1.000 & 5.000 & -1.012 & -5.179 & 1.248 & 3.192 \\
V20 & 1.000 & 5.000 & -1.060 & -5.423 & 1.693 & 4.330 \\
V10 & 2.000 & 5.000 & -.741 & -3.793 & .681 & 1.742 \\
V15 & 1.000 & 5.000 & -1.531 & -7.831 & 2.773 & 7.093 \\
V11 & 1.000 & 5.000 & -1.608 & -8.228 & 2.476 & 6.332 \\
V30 & 1.000 & 5.000 & -.747 & -3.823 & -.181 & -.463 \\
V28 & 2.000 & 5.000 & -.180 & -.919 & -.968 & -2.475 \\
V21 & 2.000 & 5.000 & -.204 & -1.042 & -.948 & -2.426 \\
V29 & 1.000 & 5.000 & -.770 & -3.940 & -.151 & -.387 \\
V24 & 1.000 & 5.000 & -.831 & -4.251 & .381 & .974 \\
V23 & 1.000 & 5.000 & -.584 & -2.988 & -.612 & -1.566 \\
V25 & 1.000 & 5.000 & -.371 & -1.898 & -.556 & -1.421 \\
\hline Multivariate & & & & & 43.473 & 10.150 \\
\hline
\end{tabular}

Table 11

The summary of Mahalanobis distance for observations farthest from the centroid

\begin{tabular}{|c|c|c|c|c|c|c|c|c|c|c|c|}
\hline $\begin{array}{l}\text { Obs. } \\
\text { number }\end{array}$ & $\begin{array}{r}\text { Mahalanobis } \\
\text { d-squared }\end{array}$ & p1 & p2 & $\begin{array}{l}\text { Obs. } \\
\text { number }\end{array}$ & $\begin{array}{r}\text { Mahalanobis } \\
\text { d-squared }\end{array}$ & $\mathrm{p} 1$ & p2 & $\begin{array}{l}\text { Obs. } \\
\text { number }\end{array}$ & $\begin{array}{r}\text { Mahalanobis } \\
\text { d-squared }\end{array}$ & $\mathrm{p} 1$ & p2 \\
\hline 48 & 52.814 & 0 & 0.004 & 126 & 23.748 & 0.163 & 0.032 & 105 & 17.598 & 0.482 & 0.876 \\
\hline 122 & 52.814 & 0 & 0 & 39 & 22.82 & 0.198 & 0.184 & 150 & 17.598 & 0.482 & 0.841 \\
\hline 64 & 39.806 & 0.002 & 0.005 & 113 & 22.82 & 0.198 & 0.137 & 25 & 17.103 & 0.516 & 0.953 \\
\hline 60 & 37.099 & 0.005 & 0.009 & 29 & 22.312 & 0.218 & 0.264 & 144 & 17.103 & 0.516 & 0.936 \\
\hline 78 & 37.099 & 0.005 & 0.001 & 148 & 22.312 & 0.218 & 0.207 & 46 & 17.064 & 0.519 & 0.923 \\
\hline 54 & 32.69 & 0.018 & 0.068 & 15 & 22.303 & 0.219 & 0.16 & 120 & 17.064 & 0.519 & 0.898 \\
\hline 72 & 32.69 & 0.018 & 0.026 & 90 & 22.303 & 0.219 & 0.119 & 36 & 16.904 & 0.53 & 0.917 \\
\hline 18 & 32.525 & 0.019 & 0.011 & 134 & 22.303 & 0.219 & 0.086 & 110 & 16.904 & 0.53 & 0.89 \\
\hline 93 & 32.525 & 0.019 & 0.003 & 8 & 21.791 & 0.241 & 0.194 & 155 & 16.904 & 0.53 & 0.857 \\
\hline 137 & 32.525 & 0.019 & 0.001 & 127 & 21.791 & 0.241 & 0.148 & 40 & 16.82 & 0.535 & 0.853 \\
\hline 26 & 32.276 & 0.02 & 0 & 9 & 21.277 & 0.266 & 0.304 & 114 & 16.82 & 0.535 & 0.814 \\
\hline 145 & 32.276 & 0.02 & 0 & 84 & 21.277 & 0.266 & 0.245 & 49 & 16.792 & 0.537 & 0.783 \\
\hline 63 & 30.515 & 0.033 & 0.002 & 128 & 21.277 & 0.266 & 0.193 & 123 & 16.792 & 0.537 & 0.733 \\
\hline 81 & 30.515 & 0.033 & 0.001 & 19 & 21.15 & 0.272 & 0.193 & 68 & 16.662 & 0.546 & 0.755 \\
\hline 59 & 30.204 & 0.036 & 0.001 & 99 & 21.15 & 0.272 & 0.149 & 62 & 16.615 & 0.55 & 0.729 \\
\hline 77 & 30.204 & 0.036 & 0 & 138 & 21.15 & 0.272 & 0.112 & 80 & 16.615 & 0.55 & 0.674 \\
\hline 37 & 29.626 & 0.041 & 0 & 55 & 20.814 & 0.289 & 0.182 & 43 & 16.497 & 0.558 & 0.691 \\
\hline 111 & 29.626 & 0.041 & 0 & 73 & 20.814 & 0.289 & 0.14 & 117 & 16.497 & 0.558 & 0.633 \\
\hline 156 & 29.626 & 0.041 & 0 & 82 & 20.814 & 0.289 & 0.105 & 67 & 15.801 & 0.606 & 0.922 \\
\hline 58 & 27.757 & 0.066 & 0.004 & 17 & 20.717 & 0.294 & 0.1 & 38 & 15.744 & 0.61 & 0.913 \\
\hline 76 & 27.757 & 0.066 & 0.002 & 92 & 20.717 & 0.294 & 0.073 & 112 & 15.744 & 0.61 & 0.885 \\
\hline 27 & 27.264 & 0.074 & 0.003 & 136 & 20.717 & 0.294 & 0.053 & 157 & 15.744 & 0.61 & 0.85 \\
\hline 146 & 27.264 & 0.074 & 0.001 & 20 & 20.52 & 0.304 & 0.067 & 21 & 15.503 & 0.627 & 0.905 \\
\hline 33 & 25.535 & 0.111 & 0.066 & 100 & 20.52 & 0.304 & 0.048 & 101 & 15.503 & 0.627 & 0.875 \\
\hline 107 & 25.535 & 0.111 & 0.041 & 139 & 20.52 & 0.304 & 0.033 & 140 & 15.503 & 0.627 & 0.838 \\
\hline 152 & 25.535 & 0.111 & 0.024 & 5 & 20.184 & 0.323 & 0.067 & 66 & 15.42 & 0.633 & 0.835 \\
\hline 22 & 24.985 & 0.125 & 0.055 & 96 & 20.184 & 0.323 & 0.048 & 45 & 15.261 & 0.644 & 0.864 \\
\hline 102 & 24.985 & 0.125 & 0.034 & 51 & 19.449 & 0.365 & 0.239 & 119 & 15.261 & 0.644 & 0.825 \\
\hline 141 & 24.985 & 0.125 & 0.021 & 125 & 19.449 & 0.365 & 0.192 & 53 & 14.993 & 0.662 & 0.896 \\
\hline 14 & 23.947 & 0.157 & 0.142 & 6 & 18.985 & 0.393 & 0.38 & 71 & 14.993 & 0.662 & 0.863 \\
\hline 89 & 23.947 & 0.157 & 0.101 & 97 & 18.985 & 0.393 & 0.32 & 34 & 14.988 & 0.663 & 0.826 \\
\hline 133 & 23.947 & 0.157 & 0.069 & 42 & 18.81 & 0.404 & 0.363 & 108 & 14.988 & 0.663 & 0.78 \\
\hline 52 & 23.748 & 0.163 & 0.073 & 116 & 18.81 & 0.404 & 0.304 & & & & \\
\hline 70 & 23.748 & 0.163 & 0.049 & 31 & 17.598 & 0.482 & 0.906 & & & & \\
\hline
\end{tabular}


Table 12 shows the results of Bootstrap selection procedure. Table 13 compares the results of Bootstrap with maximum likelihood estimator (MLE).

Table 12

The results of Bootstrap selection procedure

\begin{tabular}{lccccc}
\hline & & \multicolumn{4}{c}{ proximity of covariance structures } \\
& & GLS & ML & ADF & ULS \\
\hline \multirow{4}{*}{ Parameter estimation } & GLS & 260.4 & 1015.82 & - & 563.71 \\
& ML & 539.335 & 311.77 & - & $\mathbf{2 5 3 . 7}$ \\
& ADF & - & - & - & - \\
& ULS & - & - & - & - \\
\hline
\end{tabular}

Table 13

Comparison between MSL and Bootstrap

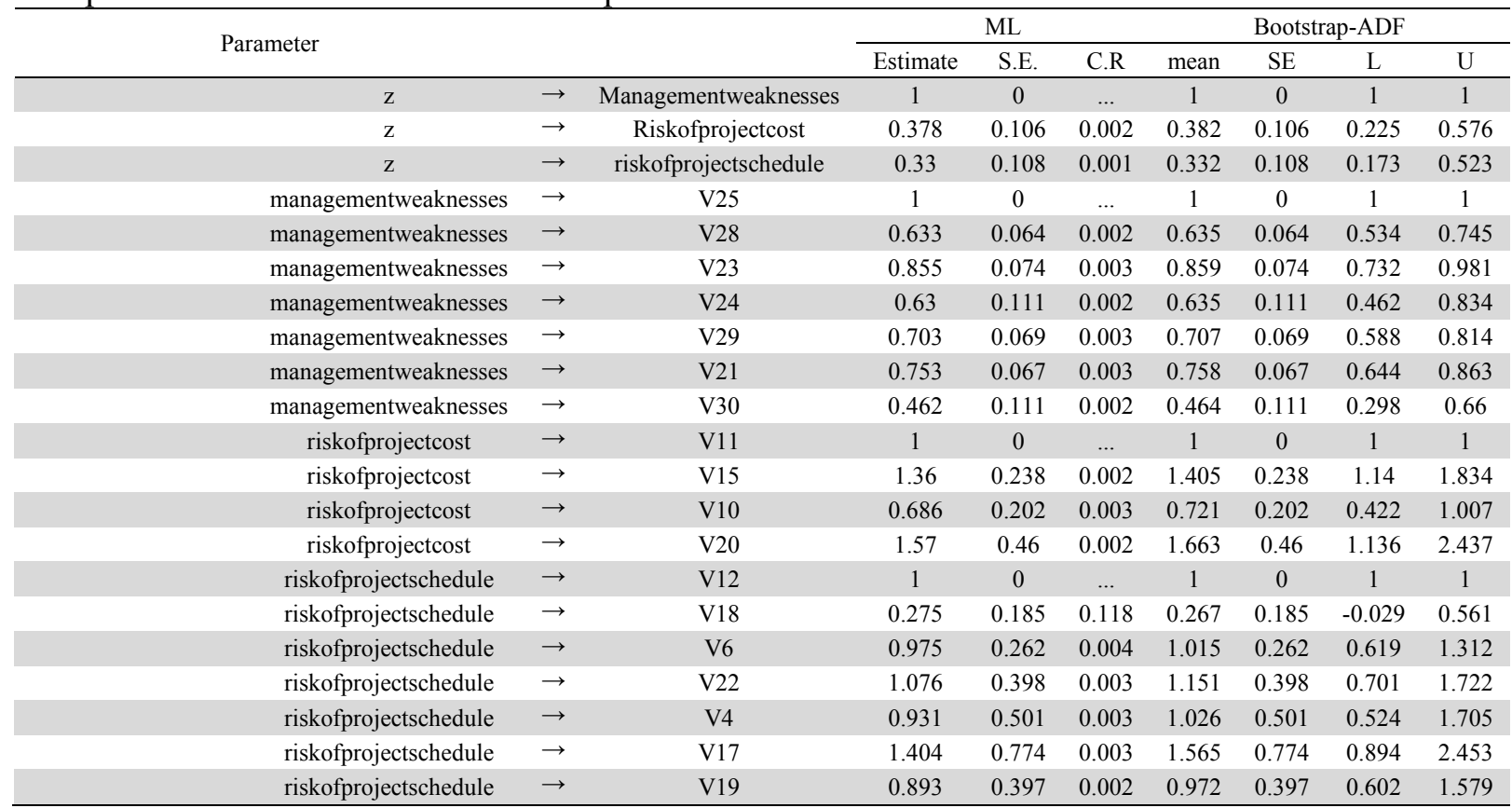

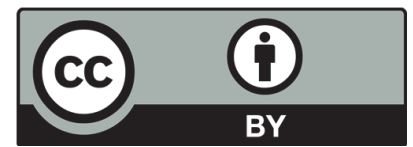

(C) 2016 by the authors; licensee Growing Science, Canada. This is an open access article distributed under the terms and conditions of the Creative Commons Attribution (CC-BY) license (http://creativecommons.org/licenses/by/4.0/). 